\title{
Management of suspected myocardial infarction before admission: updated audit
}

\author{
N Prasad, V S Srikanthan, A Wright, F G Dunn
}

Although the timing of aspirin administration is not as critical as thrombolytic treatment in patients with suspected acute myocardial infarction, aspirin should be given as soon as possible after the onset of symptoms. ${ }^{12}$ We reported a low rate $(3 \%)$ of aspirin administration by general practitioners in patients with suspected acute myocardial infarction. ${ }^{3}$ We also found a low rate of intravenous opiate administration and inappropriate use of intramuscular analgesia by general practitioners before patients were admitted to hospital. ${ }^{3}$ Most of the media's attention, however, focused on aspirin. We therefore repeated an audit of the rate of aspirin and opiate administration by general practitioners to patients with chest pain before their referral to this coronary care unit. We also assessed the final diagnosis of these patients and the frequency of aspirin prescription on discharge.

\section{Subjects, methods, and results}

In this hospital, patients arriving by ambulance can be transferred by a separate entrance to the coronary care unit for immediate assessment. ${ }^{4}$ Our audit included patients admitted consecutively to the unit over six months in 1995 after having been referred by their general practitioners for suspected acute myocardial infarction. Standard criteria were applied for diagnosing acute myocardial infarction and for prescribing thrombolysis. Patients with unstable angina were also kept in the coronary care unit. In other patients a clinical decision was made regarding their continued stay in coronary care or their transfer to a general ward for further assessment. The final diagnosis was confirmed by reviewing the case notes and the discharge letter. We classed pre-existing aspirin treatment as regular prescription (patient's self report or general practitioner's letter) or as administration of an extra dose of aspirin before admission (patient's self report or general practitioner's letter); we also noted whether aspirin had been prescribed on the discharge form. The frequency of opiate administration by general practitioners before admission was recorded. We evaluated the case notes and discharge letters for the final diagnosis and the case notes to identify any contraindications to aspirin treatment.

We studied 260 patients referred by their general practitioners (median age 64 years (range 28 to 94), 150 men); 11 were excluded because of incomplete information. The median time from the general practitioner's telephone call to admission to coronary care of a patient with suspected myocardial infarction was 40 minutes (range 2 to 217 minutes). Thirty two of 60 patients with acute myocardial infarction required thrombolytic treatment. The frequency of aspirin and opiate administration and the final diagnosis are shown in the table. Of the 19 patients with acute myocardial infarction or angina who were not prescribed aspirin, 15 did not have any contraindications to aspirin treatment. As in our previous study, around a fifth of patients were given intravenous opiates (54/249 $(22 \%)){ }^{3}$

\section{Comment}

Our study showed that many patients who have an acute myocardial infarction or ischaemic chest pain are either taking aspirin or have been given an extra dose of aspirin by their general practitioner before admission, an improvement on our previous report'; this could be improved further by prescribing aspirin on discharge.

Opiate administration before admission is still inadequate as opiates are often given intramuscularly. Such administration is relatively ineffective, falsely increases creatinine kinase concentrations and can cause intramuscular haematoma from thrombolytic treatment. $^{3}$

Contributors: NP collected and analysed data and helped in writing the report. VSS set up the database and helped with data collection. AW collected data and maintained the database. FGD devised the study and is guarantor; he wrote the report with NP.

Funding: None.

Conflict of interest: None.

1 ISIS-2 (Second International Study of Infarct Survival) Collaborative Group. Randomised trial of intravenous streptokinase, oral aspirin, both, or neither among 17187 cases of suspected acute myocardial infarction. Lancet 1988;ii:349-60.

2 British Heart Foundation Working Group. Role of the general practitioner in managing patients with myocardial infarction: impact of thrombolytic treatment. BMJ 1989;299:555-7.

3 Wyllie HR, Dunn FG. Pre-hospital opiate and aspirin administration in patients with suspected myocardial infarction. BMJ 1994;308:760-1.

4 Burns JMA, Hogg KJ, Rae AP, Hillis WS, Dunn FG. Impact of a policy of direct admission to a coronary care unit on use of thrombolytic treatment. Br Heart J 1989;61:322-5.

(Accepted 19 June 1997)
Department of Cardiology, Stobhill NHS Trust,

Glasgow G21 3UW N Prasad, specialist registrar in cardiology V S Srikanthan, research fellow

A Wright, research nurse F G Dunn, consultant cardiologist Correspondence to: Dr Dunn

BMJ 1998;316:353

Diagnosis in 249 patients referred to coronary care by general practitioners and rate of opiate and aspirin treatment before admission and of aspirin treatment on discharge. Values are numbers (percentages) of patients

\begin{tabular}{|c|c|c|c|c|c|c|c|}
\hline & \multicolumn{6}{|c|}{ Before admission } & \multirow[b]{2}{*}{$\begin{array}{c}\text { Aspirin on } \\
\text { discharge (\%) }\end{array}$} \\
\hline & $\begin{array}{c}\text { Intramuscular } \\
\text { opiates (\%) }\end{array}$ & $\begin{array}{l}\text { Intravenous } \\
\text { opiates (\%) }\end{array}$ & $\begin{array}{c}\text { Total } \\
\text { opiates (\%) }\end{array}$ & $\begin{array}{c}\text { Daily } \\
\text { aspirin (\%) }\end{array}$ & $\begin{array}{c}\text { Extra } \\
\text { aspirin (\%) }\end{array}$ & $\begin{array}{c}\text { Total } \\
\text { aspirin (\%) }\end{array}$ & \\
\hline Acute myocardial infarction $(n=60)^{*}$ & $9(15)$ & $19(32)$ & $28(47)$ & $19(32)$ & $35(58)$ & $41(68)$ & $47(87)$ \\
\hline Chest pain $(n=100) \dagger$ & $7(7)$ & $10(10)$ & $17(17)$ & $26(26)$ & $38(38)$ & $51(51)$ & $34(34)$ \\
\hline
\end{tabular}

*Six patients died in hospital. $†$ Non-specific or other diagnosis. 